\title{
Thermo stabilisation of poly (butylene adipate-co-terephthalate)
}

\author{
Rodrigo Paulino Chaves ${ }^{1}$ and Guilhermino José Macêdo Fechine ${ }^{2 *}$
}

\author{
'Materials Engineering Department, Engineering School, Universidade Presbiteriana Mackenzie, \\ São Paulo, SP, Brazil \\ ${ }^{2}$ Graphene and Nano-materials Research Center - MackGraphe, Universidade Presbiteriana Mackenzie, \\ São Paulo, SP, Brazil \\ *guilherminojmf@mackenzie.br
}

\begin{abstract}
Poly (butylene adipate-co-terephthalate) - PBAT is a synthetic biodegradable polymer commonly used for plastic film production from neat polymer or nanocomposites. The PBAT is submitted to high temperatures and shear rate during its processing. In the present study, the thermo stabilisation of PBAT by the addition of two types of stabilisers was studied using a torque rheometer at $60 \mathrm{rpm}$ and two levels of temperature. The stabilisers were used as master batches with a percentage of $10 \%$ by weight of additive in the PBAT. Molecular weight, torque values after 10 minutes of mixing, and absorbance at $400 \mathrm{~nm}$ were used to evaluate the process of stabilisation. The primary and secondary antioxidant used here had a positive effect on both processing temperatures, 180 and $200{ }^{\circ} \mathrm{C}$. The best results indicate that the primary antioxidant could be used alone to protect PBAT against thermodegradation reactions.
\end{abstract}

Keywords: biodegradable polymer, poly (butylene adipate-co-terephthalate), thermo stabilisation.

\section{Introduction}

The main applications of biodegradable polymers do not require high mechanical strength like packaging, disposable non-woven, sanitary products, consumables and agricultural tools ${ }^{[1]}$. Biodegradable polymers still face some problems in their use due to their low performance when subjected to applications that need high strength, whether chemical, physico-chemical and/or mechanical. However, advancements in research for better mechanical properties in biodegradable polymers ${ }^{[2,3]}$ and environmental problems like pollution, largely influenced by conventional polymers ${ }^{[4,5]}$ led to the enhancement of biodegradable polymer production. The greatest concern about biodegradable polymers is the time of the biodegradation and bioassimilation of them during the degradation process induced by microorganisms. ${ }^{[6,7]}$ The biodegradation of some polymers is governed by the attack of the micro-organisms at ester linkage that enables a rapid fragmentation. This same linkage is very sensitive to the degradative process caused by high temperature and shear rates as well as hydrolysis due to the presence of moisture. The exposure to these degradation conditions could occur mainly during processing (extrusion and injection moulding). Few researchers have presented studies about thermostabilisation of the biodegradable polymers ${ }^{[8]}$. Poly (butylene adipate-co-terephthalate) - PBAT is a synthetic biodegradable copolymer, specifically a copolyester of adipic acid, 1, 4-butanediol and dimethyl terephthalate. It is commonly used for plastic film production ${ }^{[9]}$. The polymer processing to produce films or to obtain nanocomposites based on PBAT is carried out at high temperatures and shear rate during its processing. Al-Itry et al. ${ }^{[10]}$ proposed the degradation mechanism of PBAT during processing based on hydrolysis of ester linkage, main-chain scissions and $\beta-\mathrm{C}-\mathrm{H}$ hydrogen transfer. The choice of stabilisers is very important to keep the physical properties of PBAT after processing and it is dependent of action mechanism of the stabilisers. Here, the objective of this study is to evaluate the thermo-mechanical stabilisation of PBAT through the use of antioxidants (primary and secondary), using a torque rheometer as a processing and analysis tool. Torque monitoring after 10 minutes, analysis of molecular weight measurements by size exclusion chromatography (SEC) and UV/Vis were used to assess degradation and stabilisation of PBAT. The idea includes not only the evaluation of thermostabilisation of PBAT but also simplifies the method of this analysis.

\section{Experimental}

In this work, commercial PBAT was used. The stabilisers used in this work were Irganox 1010 (primary antioxidant - P, $0.4 \mathrm{w} / \mathrm{w} \%$ ) and Irgafos 168 (secondary antioxidant - S, $0.5 \mathrm{w} / \mathrm{w} \%$ ). As the concentrations of additives are very low, it was preferred to prepare master batches with a percentage of $10 \%$ by weight of additive in the PBAT. After that, a fresh mixture with pure PBAT and master batch was made to achieve the desired concentrations. The preparation of the concentrates was carried out in a mechanical mixer and then they were cut in a knife mill to obtain smaller sizes. The thermo-mechanical degradation was performed on a torque rheometer at $60 \mathrm{rpm}$ for $10 \mathrm{~min}$. Two levels of temperature inside the rheometer were used, 180 and $200^{\circ} \mathrm{C}$. PBAT and PBAT/master batch were dried in an oven for 1 hour at $70{ }^{\circ} \mathrm{C}$ before processing. The evaluation of the stabilisation process was done by analysing the torque value after 10 minutes, Size Exclusion Chromatography (SEC) 
and UV/Vis spectroscopy. SEC analyses were conducted in a Viscoteck with a series of columns at $40^{\circ} \mathrm{C}$ and with a refractive index detector. Specimens were dissolved in THF and the filtered solution was injected into the equipment. The solvent flow rate (THF) was $1 \mathrm{~mL} / \mathrm{min}$ and the columns were calibrated with narrow molecular weight PS. The UV-visible spectroscopy analysis was done with the samples in chloroform solution $\left(0.01 \mathrm{~g} / \mathrm{cm}^{3}\right)$ using a Shimadzu 1501 equipment.

\section{Results and Discussion}

Table 1 presents values of $\bar{M}_{n}, \bar{M}_{w}$, polydispersity (PD), torque after 10 minutes, and absorbance at $400 \mathrm{~nm}$ for neat PBAT and PBAT + additives processed at the rheometer for 10 minutes under 180 and $200{ }^{\circ} \mathrm{C}$. Molecular weight data in Table 1 indicates that temperature has a great influence on the thermodegradation of PBAT since there is a higher drop of molecular weight values for samples without stabilisers processed at $200{ }^{\circ} \mathrm{C}$ when compared with those processed at $180^{\circ} \mathrm{C}$. At the same time, the value of polydispersity has increased. These results indicated that the process involved in the thermodegradation of PBAT is governed by the scission chain reactions ${ }^{[11,12]}$. This hypothesis is confirmed by the rheometric data since the values of torque at $10 \mathrm{~min}$ has decreased significantly at $200{ }^{\circ} \mathrm{C}$. In the case of the additives at $180^{\circ} \mathrm{C}$, there is no significant difference between the action of primary and secondary antioxidants taking into account only molecular weight and torque data. Values of molecular weight remained almost unchanged for $180^{\circ} \mathrm{C}$ compared with neat PBAT and torque values at 10 min were quite similar for the three compositions. It is a good indication of thermostabilisation of PBAT by the two additives used here. However, the expected synergetic effect between primary and secondary antioxidant did not occur clearly, Molecular weight data for samples with additives processed at $200{ }^{\circ} \mathrm{C}$ under process conditions used here show that the additives also have a positive effect. There is no trend with regard to polydispersity; it is probable that scissions and crosslinking reactions competed during the thermodegradation process of PBAT. Torque values at 10 minutes are lower than samples processed at $180^{\circ} \mathrm{C}$, therefore, higher than samples without additives. Higher temperatures led to a strong thermodegradation of PBAT even in a presence of additives. Absorbance at $400 \mathrm{~nm}$ of the polymer solutions are used to describe two types of phenomena, an increase of chromophore groups or high dispersion of the light due to insoluble fragments of polymer from crosslinking reactions ${ }^{[13]}$. In both temperatures, the presence of additives decreased the absorbance at $400 \mathrm{~nm}$ indicating the positive action of the stabilisers against of thermodegradation reactions. The highest decrease of $\mathrm{Abs}_{400 \mathrm{mn}}$ is for the sample processing at $180^{\circ} \mathrm{C}$ in the presence of secondary stabiliser. Probably, the additives could prevent the crosslinking reactions at this temperature but not the chain scissions since the drop of molecular weight is quite the same for the samples processing with primary stabiliser alone or in combination with secondary one.

Figure 1 shows rheometer torque curves of PBAT processed at 180 and $200^{\circ} \mathrm{C}$ without and in the presence of stabilisers. As can be seen, all compositions with stabilisers at both temperatures led to torque values above PBAT without stabilisers. The action of stabilisers was stronger for lower temperature $\left(180^{\circ} \mathrm{C}\right)$ and the primary oxidant alone was more efficient than the secondary one and the combination of primary and secondary. The primary stabilisers act directly on the deactivation of free radicals and the secondary ones act on the deactivation of free radicals or hydroperoxide decomposition ${ }^{[14]}$. It is an indication that thermostabilisation of PBAT is strongly driven by the deactivation of the free radicals when compared with the decomposition of hydroperoxides.

Figure 2 shows molecular weight distribution curves of neat PBAT and PBAT processed at 180 and $200^{\circ} \mathrm{C}$ without stabilisers and with stabilisers. In the case of PBAT processed at both temperatures, clearly, it is verified that the molecular weight curve is displaced strongest to lower molecular weight when the polymer is processed with no stabiliser. However, the best stabiliser effect is obtained by the presence of the primary antioxidant alone for both temperature conditions. These results are in agreement with torque and UV/Vis results. It could be an indication that deactivation of free radicals reactions are more important to PBAT than hydroperoxide decomposition ones or the mechanism of degradation of PBAT is not governed by generation of hydroperoxides groups.

Table 1. Molecular weight, torque and UV/Vis data of PBAT samples processed without and with stabilisers at two different temperatures.

\begin{tabular}{|c|c|c|c|c|c|}
\hline Sample/Temperature & $\begin{array}{c}\bar{M}_{n} \\
(\mathrm{~g} / \mathrm{mol})\end{array}$ & $\begin{array}{c}\bar{M}_{w} \\
(\mathrm{~g} / \mathrm{mol})\end{array}$ & PD & $\begin{array}{l}T_{10 \min } \\
\text { (N.m) }\end{array}$ & $\begin{array}{c}\mathbf{A b s}_{400 \mathrm{~nm}} \\
\text { (u.a.) }\end{array}$ \\
\hline Neat PBAT & 40.600 & 84.400 & 2.08 & - & 0.00829 \\
\hline $\mathrm{PBAT} / 180^{\circ} \mathrm{C}$ & 36.450 & 76.950 & 2.11 & 1.8 & 0.03297 \\
\hline $\operatorname{PBAT} / 200^{\circ} \mathrm{C}$ & 33.250 & 70.200 & 2.11 & 1.5 & 0.03928 \\
\hline $\mathrm{PBAT}+\mathrm{P} / \mathbf{1 8 0}{ }^{\circ} \mathrm{C}$ & 40.500 & 80.000 & 1.97 & 4.5 & 0.02516 \\
\hline $\mathrm{PBAT}+\mathrm{S} / 180^{\circ} \mathrm{C}$ & 39.750 & 80.900 & 2.03 & 4.1 & 0.01699 \\
\hline $\mathrm{PBAT}+\mathrm{PS} / 180^{\circ} \mathrm{C}$ & 39.700 & 79.100 & 1.99 & 4.0 & 0.02539 \\
\hline $\mathrm{PBAT}+\mathrm{P} / 200{ }^{\circ} \mathrm{C}$ & 40.100 & 78.300 & 1.95 & 2.6 & 0.02216 \\
\hline $\mathrm{PBAT}+\mathrm{S} / 200{ }^{\circ} \mathrm{C}$ & 36.850 & 74.000 & 2.01 & 2.5 & 0.02516 \\
\hline $\mathrm{PBAT}+\mathrm{PS} / 200^{\circ} \mathrm{C}$ & 38.300 & 74.700 & 1.95 & 2.0 & 0.02321 \\
\hline
\end{tabular}




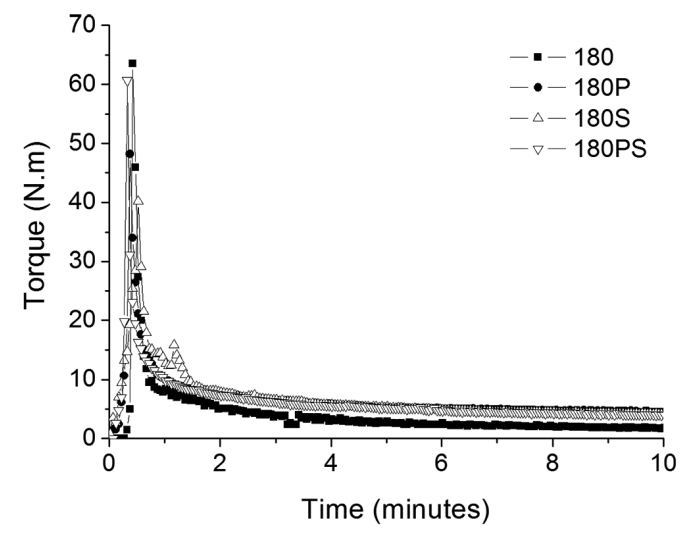

(a)

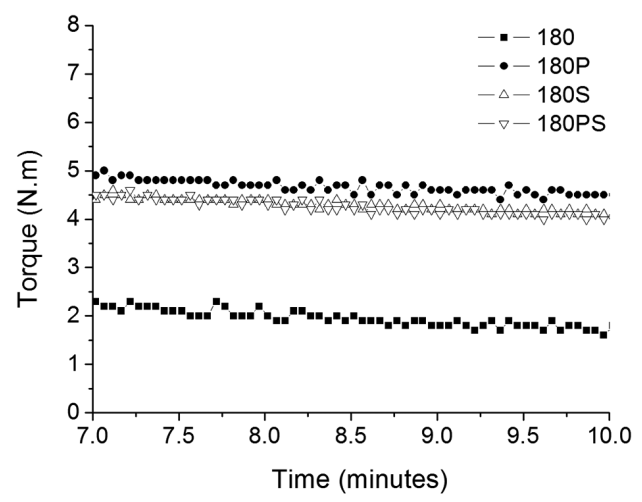

(c)

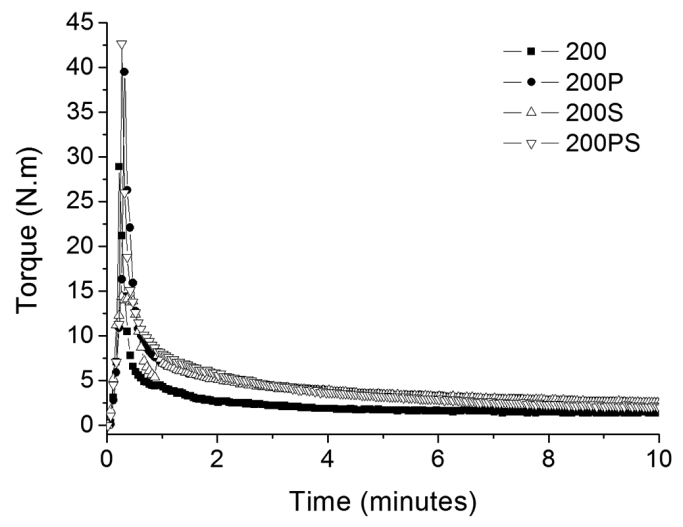

(b)

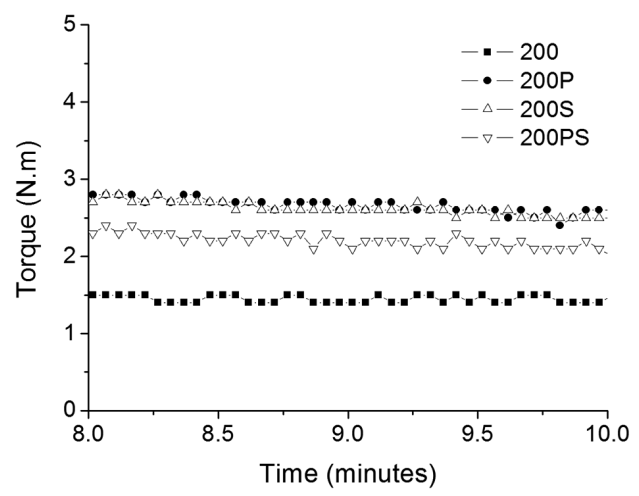

(d)

Figure 1. Rheometer torque curves of PBAT processed at 180 (a) and $200{ }^{\circ} \mathrm{C}$ (b) without stabilisers and with stabilisers $\mathrm{P}=$ primary antioxidant $\mathrm{S}=$ secondary oxidant, $\mathrm{PS}=\mathrm{P}+\mathrm{S}$. Detailed curves around 10 minutes for 180 (c) and $200{ }^{\circ} \mathrm{C}(\mathrm{d})$.

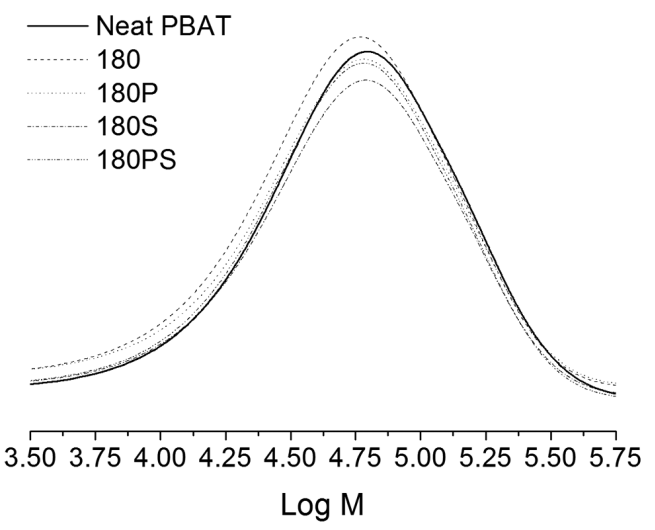

(a)

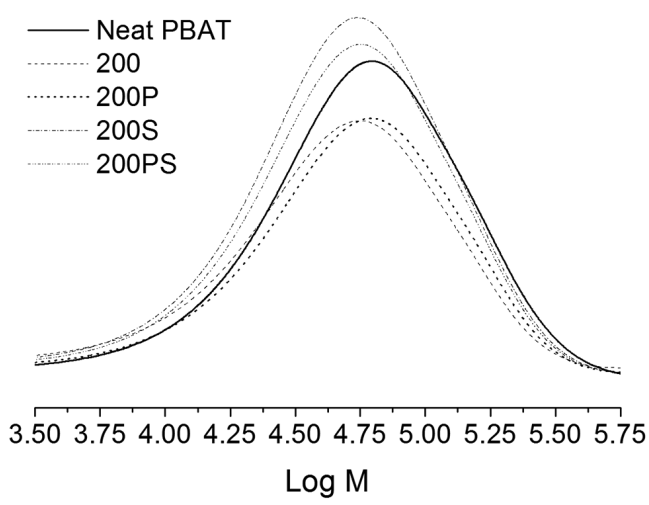

(b)

Figure 2. Molecular weight distribution curves of neat PBAT and PBAT processed at 180 (a) and $200{ }^{\circ} \mathrm{C}$ (b) without stabilisers and with stabilisers $\mathrm{P}=$ primary antioxidant $\mathrm{S}=$ secondary oxidant, $\mathrm{PS}=\mathrm{P}+\mathrm{S}$.

\section{Conclusions}

In this work, the thermo stabilisation of PBAT was studied using a torque rheometer and two types of stabilisers (primary and secondary antioxidant). Molecular weight, torque values after 10 minutes of mixing, and absorbance at $400 \mathrm{~nm}$ were used to evaluate the process of stabilisation. The results show that these two types of stabilisers worked very well, both alone and together, however, with the concentrations used here the primary antioxidant is the best choice to stabilise PBAT during processing. However, a better control of the drying of the samples must be performed to avoid 
the hydrolysis reactions which can not be prevented by the action of stabilisers. Here, it is very important to highlight that nothing could be predicted concerning prolonged use of the stabilisers since the data were acquired on a ten-minute range. The torque rheometer technique proved to be able to generate results in a simple way and with indicators for the best choice of stabiliser.

\section{Acknowledgements}

The authors are grateful to FAPESP(Process 2010/07651-9) and CNPq (Process 304902/2012-8) Brazilian funding agencies for the financial support.

\section{References}

1. Bastioli, C. (2005). Handbook of biodegradable polymers. United Kingdom: Rapra Technology.

2. Lee, S. M., Cho, D., Park, W. H., Lee, S. G., Han, S. O., \& Drzal, L. T. (2005). Novel silk/poly(butylene succinate) biocomposites: the effect of short fibre content on their mechanical and thermal properties. Composites Science and Technology, 65(3-4), 647-657. http://dx.doi.org/10.1016/j. compscitech.2004.09.023.

3. Bordes, P., Pollet, E., \& Avérous, L. (2009). Nano-biocomposites: Biodegradable polyester/nanoclay systems. Progress in Polymer Science, 34(2), 125-155. http://dx.doi.org/10.1016/j. progpolymsci.2008.10.002.

4. Baeyens, J., Brems, A., \& Dewil, R. (2010). Recovery and recycling of post-consumer waste materials. Part 2. Target wastes (glass beverage bottles, plastics, scrap metal and steel cans, end-of-life tyres, batteries and household hazardous waste). International Journal of Sustainable Engineering, 3(4), 232-245. http://dx.doi.org/10.1080/19397038.2010.507885.

5. Coelho, T. M., Castro, R., \& Gobbo, J. A., Jr (2011). PET containers in Brazil: Opportunities and challenges of a logistics model for post-consumer waste recycling. Resources, Conservation and Recycling, 55(3), 291-299. http://dx.doi. org/10.1016/j.resconrec.2010.10.010.
6. Chandra, R., \& Rustgi, R. (1998). Biodegradable polymers. Progress in Polymer Science, 23(7), 1273-1335. http://dx.doi. org/10.1016/S0079-6700(97)00039-7.

7. Luckachan, G. E., \& Pillai, C. K. S. (2011). Biodegradable polymers: a review on recent trends and emerging perspectives. Journal of Polymers and the Environment, 19(3), 637-676. http://dx.doi.org/10.1007/s10924-011-0317-1.

8. Amorin, N. S. Q. S., Rosa, G., Alves, J. F., Gonçalves, S. P. C., Franchetti, S. M. M., \& Fechine, G. J. M. (2014). Study of thermodegradation and thermostabilization of poly(lactide acid) using subsequent extrusion cycles. Journal of Applied Polymer Science, 131(6), 1-8. http://dx.doi.org/10.1002/app.40023.

9. Bilck, A. P., Grossmann, M. V. E., \& Yamashita, F. (2010). Biodegradable mulch films for strawberry production. Polymer Testing, 29(4), 471-476. http://dx.doi.org/10.1016/j. polymertesting.2010.02.007.

10. Al-Ltry, R., Lamnawara, K., \& Maazouz, A. (2012). Improvement of thermal stability, rheological and mechanical properties of PLA, PBAT and their blends by reactive extrusion with functionalized epoxy. Polymer Degradation \& Stability, 97(10), 1898-1914. http://dx.doi.org/10.1016/j.polymdegradstab.2012.06.028.

11. Rabello, M. S., \& White, J. R. (1997). Fotodegradação do polipropileno: um processo essencialmente heterogêneo. Polimeros: Ciência e Tecnologia, 7(2), 47-57. http://dx.doi. org/10.1590/S0104-14281997000200007.

12. Cáceres, C. A., \& Canevarolo, S. V. (2008). Cisão de cadeia na degradação termo-mecânica do poliestireno sob múltiplas extrusões. Polímeros: Ciência e Tecnologia, 18(4), 348-352. http://dx.doi.org/10.1590/S0104-14282008000400015.

13. Timóteo, G. A. V., Fechine, G. J. M., \& Rabello, M. S. (2007). Stress Cracking and Photodegradation: The Combination of Two Major Causes of HIPS Failure. Macromolecular Symposia, 258(1), 162-169. http://dx.doi.org/10.1002/masy.200751218.

14. Rabello, M. S., \& De Paoli, M. (2013). Aditivação de termoplásticos, São Paulo: Artliber Editora Ltda.

Received: May 20, 2015

Revised: Jan. 11, 2016

Accepted: Feb. 15, 2016 